\title{
The feasibility of using soil runoff in calculating the water balance of ameliorated soil
}

\author{
Ivan Levshunov ${ }^{1}$, Yuri Mazhayskiy ${ }^{1}$, and Olga Chernikova ${ }^{2, *}$ \\ ${ }^{1}$ Belarusian State Agricultural Academy, Gorki, Ivan Michurin str., 5, Belarus \\ ${ }^{2}$ Academy of law management of the federal penal service of Russia, 390036 Ryazan, Sennaya str., 1, \\ Russian Federation
}

\begin{abstract}
The water regime on the reclaimed lands changes significantly during the year, and its possible change must be established or predicted in advance at the project stage. From the main characteristics of the water regime of soil, it is possible to reliably predict changes in moisture reserves and, worse, the dynamics of groundwater levels. Prediction of changes in moisture reserves in soil is carried out using "water balance calculations". The results of long-term field research have shown that the main factors causing surface runoff are: the amount and intensity of precipitation, the initial moisture content of the upper soil layers, the slope and condition (agricultural use) of the site surface. The feasibility of using a variable runoff boundary in calculating the water balance of ameliorated soil is shown. The results of field experiments on the study of surface runoff in conditions of loamy soil are presented. Two-factor dependences of the daily runoff from precipitation and soil moisture have been obtained in case of its various agricultural uses.
\end{abstract}

\section{Introduction}

The water balance of the root layer of the soil forms the basis for assessing its water regime and substantiating the project and operating regimes of hydro amelioration. The problem of rational use of soil moisture reserves, excluding unproductive runoff, the volume of which can be spent on water consumption of agricultural crops arises with the artificial regulation of the water regime of soil [1,2].

The soil water balance equations used in specific practical calculations, as a rule, represent the algebraic sum of its input and output elements. In this case, the main input elements are atmospheric precipitation $(\mathrm{P}, \mathrm{mm})$ and recharge of the calculated soil layer from groundwater (Wrp, $\mathrm{mm}$ ), and the main consumable components are total evaporation $(\mathrm{E}, \mathrm{mm})$ and soil runoff $(\mathrm{C}, \mathrm{mm})$.

It is known that to ensure objective calculation results, all components of the water balance equation must comply with the principle of equal accuracy. Meanwhile, the analysis of special literature and previously performed field experiments [3-9] shows that

\footnotetext{
* Corresponding author: chernikova_olga@inbox.ru
} 
when calculating the water balance of ameliorated soil, the soil runoff is the least justified value in comparison with other elements of the water balance. This is confirmed by the fact that in most calculation methods the value of soil runoff is calculated as the excess of the current moisture reserves of the soil $\left(\mathrm{W}_{\mathrm{i}}, \mathrm{mm}\right)$ over the upper limit of their regulation, equal to the lowest moisture capacity $\left(\mathrm{W}_{\mathrm{Hв}}, \mathrm{mm}\right)$. In this case, this restriction is introduced, as a rule, regardless of the filtration properties of the soil, discretization (time interval) of calculations and other conditions that determine the inertia and dynamics of soil runoff.

Experimental water balance studies carried out earlier in the conditions of the Goretskiy region $[1,2]$ in particular showed that in case of significant wetting of loamy soil with precipitation, its moisture content for a long time (more than a decade) can exceed the HB level. In this case, the actual value of soil runoff for the calculated interval within a decade turns out to be less than the excess of soil moisture reserves over $\mathrm{W}_{\text {нв }}$. A significant change (increase) in the calculated soil runoff was revealed with a decrease in the calculation interval from a decade to a day. As a result (according to the author's data), there was a corresponding overestimation of the irrigation rate of the pasture to $30-45 \%$. Based on this, he concluded that it is advisable to increase the accumulating capacity and the calculated soil layer from 0.3 to $0.5 \mathrm{~m}$, which partially smoothes the growth of unproductive runoff as the calculation interval decreases.

However, our analysis of field experiments and similar model calculations are convincing that this approach does not eliminate the initial cause of the "instability" of water balance calculations, which in fact consists in the lack of taking into account the inertia of the actual process of soil runoff. Computer calculations of the water balance of perennial grasses based on the experimental and meteorological data of the educational and experimental irrigation complex "Tushkovo-1" of the Goretskiy region confirmed the fact of a significant increase in the estimated runoff caused by its different dynamics with a reduction in discretization of calculations. Under the conditions of the growing season, when the estimated interval from a month to a day was assigned, the seasonal runoff on loamy soil took values from 3 to $45 \mathrm{~mm}$ [2].

\section{Methods}

In order to take into account the different dynamics of soil runoff, depending on the granulometric composition of mineral soil and the introduction of the variable runoff boundary above the $\mathrm{W}_{\text {нв }}$ level, in the previously developed by V.I. Vikhrov algorithms of computer programs for retrospective modeling of soil water regime (RETRO - 1,2,3) [1], the value of ten-day soil runoff $(\mathrm{Ci}, \mathrm{mm})$ is determined on the basis of the following relation

$$
\mathrm{C}^{\mathrm{i}}=\mathrm{K}_{\mathrm{C}}\left(\mathrm{W}^{\mathrm{i}}{ }_{\mathrm{K}}-\mathrm{W}^{\mathrm{H}}{ }_{\mathrm{B}}\right) \text {, }
$$

where $W^{i}{ }_{K}$ - soil moisture reserves at the end of the $i$-th decade, exceeding the lowest moisture capacity $\mathrm{W}^{\mathrm{H}}{ }_{\mathrm{B}}, \mathrm{mm}$; $\mathrm{K}_{\mathrm{C}}$ is the coefficient of soil runoff, which depends on the granulometric composition of the soil $\left(K_{\mathrm{C}} \leq 1\right)$.

At this stage of research, the value of the $\mathrm{KC}$ in the ten-day interval of calculations is recommended to be taken equal to $1.0 ; 0.95$ and 0.85 , respectively, for light, medium and heavy mineral soil in terms of granulometric distribution.

To assess the influence of the variable runoff boundary using formula (1) on the reduction of its project seasonal values and irrigation rates, retrospective calculations of the water balance of loamy soil were performed under conditions of irrigation reclamations (RETRO-2 program) and drainage-moisture reclamations (RETRO-3 program) according 
to data from five meteorological stations in the north-eastern part of the Republic of Belarus.

The calculations were carried out for two options: a) with a constant runoff boundary (at $\left.K_{C}=1\right)$; b) with a variable border ( at $\left.K_{C}=0.85\right)$. The results of calculations performed for the period from 1945 to 2005 for late cabbage are given in the $1^{\text {st }}$ table. The values of $\Delta \mathrm{M}_{25 \%}, \Delta \mathrm{C}_{25 \%}$ are the difference between the values of $\mathrm{M}_{25 \%}, \mathrm{C}_{25 \%}$ of "a" and "b" options.

Table 1. Influence of the soil runoff coefficient on the project parameters of irrigation rates $\left(\mathrm{M}_{25 \%}\right)$ and seasonal runoff $\left(\mathrm{C}_{25 \%}\right)$ of $25 \%$ supply in conditions of loamy soil under late cabbage

\begin{tabular}{|c|c|c|c|c|c|c|}
\hline \multirow[b]{2}{*}{$\begin{array}{l}\text { Weather } \\
\text { station }\end{array}$} & \multicolumn{2}{|c|}{$\mathrm{K}_{\mathrm{C}}=1$} & \multicolumn{2}{|c|}{$K_{C}=0,85$} & \multirow[b]{2}{*}{$\begin{array}{c}\Delta \mathrm{M}_{25 \%} \\
\%\end{array}$} & \multirow[b]{2}{*}{$\begin{array}{c}\Delta \mathrm{C}_{25 \%}, \\
\%\end{array}$} \\
\hline & $\begin{array}{l}\mathrm{M}_{25 \%}, \mathrm{~mm} \\
\text { (RETRO- } \\
\text { 2) }\end{array}$ & $\begin{array}{c}\mathrm{C}_{25 \%}, \mathrm{~mm} \\
(\mathrm{RETRO}- \\
3) \\
\end{array}$ & $\begin{array}{c}\mathrm{M}_{25 \%}, \mathrm{~mm} \\
(\mathrm{RETRO}- \\
\text { 2) }\end{array}$ & $\begin{array}{c}\mathrm{C}_{25 \%}, \mathrm{~mm} \\
(\mathrm{RETRO}- \\
3)\end{array}$ & & \\
\hline Bobruisk & 152 & 145 & 141 & 130 & 7,2 & 10,3 \\
\hline Vitebsk & 114 & 190 & 104 & 170 & 8,8 & 10,5 \\
\hline Gorki & 131 & 170 & 122 & 155 & 6,9 & 8,8 \\
\hline Kostyukovichi & 165 & 155 & 152 & 144 & 7,9 & 7,1 \\
\hline Mogilev & 147 & 137 & 138 & 126 & 6,1 & 8,0 \\
\hline Average & 142 & 159 & 131 & 145 & 7,7 & 8,8 \\
\hline
\end{tabular}

As the data in the $1^{\text {st }}$ Table show, the introduction of a variable runoff boundary at $K_{\mathrm{C}}=$ 0.85 in ten-day calculations makes it possible to save irrigation norms and seasonal runoff with a $25 \%$ supply on average by 7.7 and $8.8 \%$, respectively. In some real years, this watersaving effect can be much greater. For example, the irrigation rates of late cabbage for "a" and "b" options, calculated using the Gorki weather station were 99.8 and $52.1 \mathrm{~mm}$, respectively, in 1995; seasonal runoff was 156 and $108 \mathrm{~mm}$, respectively. This made it possible to reduce the required number of irrigations from three to two.

In the calculations using the RETRO-2 program, we used the variant with a deep groundwater table (GWL) and with a variable lower limit of the optimal soil moisture, taking into account the mean ten-day effective air temperature.

The algorithm of the RETRO-3 program is based on the relationship between the water balance of the root-inhabited layer of the ameliorated soil and the ten-day GWL dynamics, regulated within the required safe range. In this case, the drainage runoff of mineral and peat soil is calculated, respectively, according to the formulas obtained by V.I. Vikhrov [6]:

$$
\begin{aligned}
& \mathrm{C}_{\text {д }}^{\mathrm{i}}=56 \sqrt{\mathrm{K}_{\phi}}\left(\Delta \mathrm{H}_{\text {д }}^{\mathrm{i}}\right)^{1,333} ; \\
& \mathrm{C}_{\text {д }}^{\mathrm{i}}=116 \mathrm{~K}_{\phi}{ }^{0,375}\left(\Delta \mathrm{H}_{\text {д }}^{\mathrm{i}}\right)^{1,750},
\end{aligned}
$$

where $\mathrm{C}_{{ }^{2}}^{\mathrm{i}}$ - drainage runoff of the $\mathrm{i}$-th decade, $\mathrm{mm} ; \mathrm{K}_{\phi}$ - coefficient of soil filtration in the zone of GWL regulation, $\mathrm{m} /$ day; $\Delta \mathrm{H}_{д}^{\mathrm{i}}$ - required GWL reduction provided by drainage runoff, $m$.

Formulas (2) and (3) were obtained on the basis of the transformation of the water balance relation between the values of $\mathrm{K}_{\mathrm{f}}, \Delta \mathrm{H}_{\mathrm{d}}^{\mathrm{i}}$ and the calculated water loss of mineral and peat soil $(\delta)$, determined, respectively, by the known dependences of G.D. Erkin and A.I. Ivitskiy. 


\section{Results and Discussion}

The results of long-term field research have shown that the main factors causing surface runoff are: the amount and intensity of precipitation, the initial moisture content of the upper soil layers, the slope and condition (agricultural use) of the site surface.

Since these factors act independently and in parallel, at the first stage of the analysis, a one-factor correlation between the daily surface runoff and the amount of daily precipitation for individual runoff sites was investigated. At the same time, to take into account the influence of the initial soil moisture on the runoff, all the runoff data measured at the plots were divided into three separate samples with different moisture ranges of the upper 20-cm soil layer $\mathrm{W}_{\mathrm{H}}$ : $1-\left(\mathrm{W}_{\mathrm{H}}>1.2 \mathrm{~W}_{\mathrm{HB}}\right) ; 2-\left(\mathrm{W}_{\mathrm{H}}=0.8-1.2 \mathrm{~W}_{\mathrm{HB}}\right) ; 3-\left(\mathrm{W}_{\mathrm{H}}<0.8\right.$ $\mathrm{W}_{\mathrm{HB}}$ ). This differentiation of the studied samples made it possible to reduce the heterogeneity of empirical data on the factor of soil moisture.

Regression analysis of the experimental data showed that the most acceptable form of correlation between the studied samples of surface runoff with precipitation is a exponential function (with an exponent $b>1$ ):

$$
\mathrm{C}_{\Pi}=\mathrm{aP}^{\mathrm{b}}
$$

where $C_{n}$ - the daily surface runoff, mm; P - value of daily precipitation, mm; a, b empirical coefficients.

An example of the indicated dependence (4) for the runoff site No. 5 is shown in the Fig. 1. The obtained similar plots for other sites show that the most significant effect of precipitation on surface runoff is observed at soil moisture $\mathrm{W}_{\mathrm{H}}>1.2 \mathrm{~W}_{\mathrm{HB}}$. At the same time, a certain runoff is also found under the condition $\mathrm{W}_{\mathrm{H}}<\mathrm{W}_{\mathrm{HB}}$, which can be explained by the waterlogging of the uppermost layers of loamy soil with a high intensity of rain.

\section{$\mathrm{Cn}, \mathrm{mm}$}

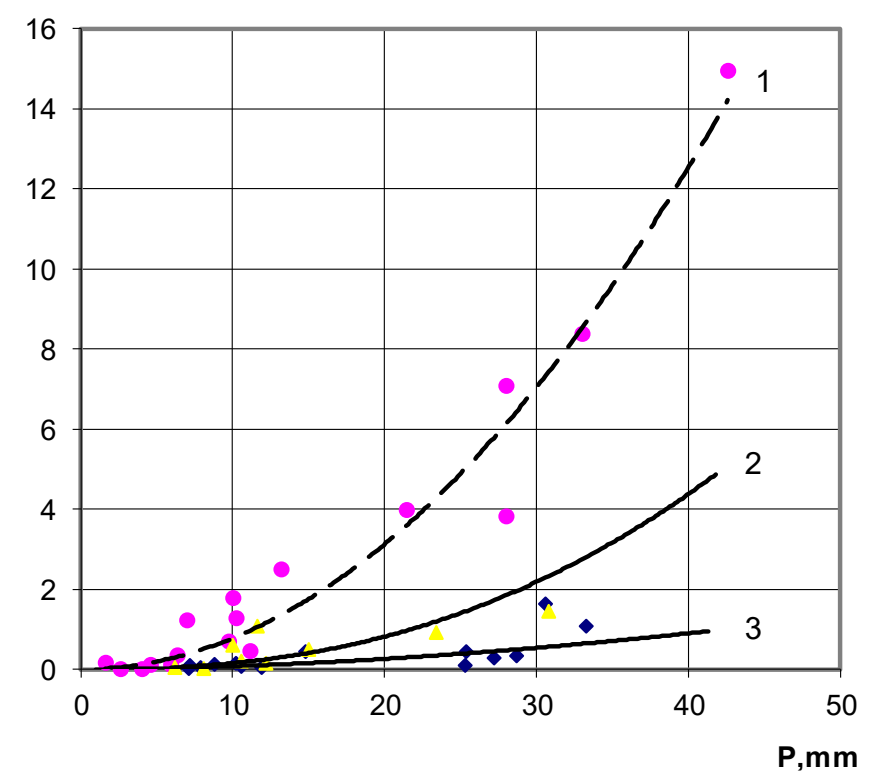

Fig. 1. Relation between daily values of surface runoff and precipitation at runoff site No. 5 at different ranges of soil moisture $\mathrm{W}_{\mathrm{H}}$ (explanations in the text) 
When substantiating the two-factor dependence of runoff on precipitation and initial soil moisture, we used the method of transformation and sequential introduction of variables [2].

As the result of computer processing, the calculated two-factor dependences for the surface runoff were obtained:

$$
\mathrm{C}_{\mathrm{n}}=\mathrm{aP}_{\mathrm{o}}{ }^{\mathrm{b}} \mathrm{W}_{\mathrm{H}}^{\mathrm{b}_{1}}
$$

where $\mathrm{P}_{0}$ - daily precipitation, expressed in $\mathrm{cm}$ of layer $\left(\mathrm{P}_{0}=\mathrm{P} / 10\right)$; $\mathrm{W}_{\mathrm{H}}$ - initial moisture reserves of the soil in the 0-20 cm layer in fractions of $\mathrm{W}_{\mathrm{HB}}$; $\mathrm{a}, \mathrm{b}, \mathrm{b}_{1}$ - empirical coefficients.

An example of a two-factor function (5) for the runoff site No. 5 is shown in the Fig. 2.

The values of the empirical coefficients and the correlation ratio $r$ of dependence (5) for individual drainage sites are given in the $2^{\text {nd }}$ Table.

The number of experimental data when obtaining the two-factor dependence (5) was taken to be the same for all areas and amounted to 40 parallel measurements of $\mathrm{C}_{\Pi}, \mathrm{P}_{0}$ and $\mathrm{W}_{\mathrm{H}}$.

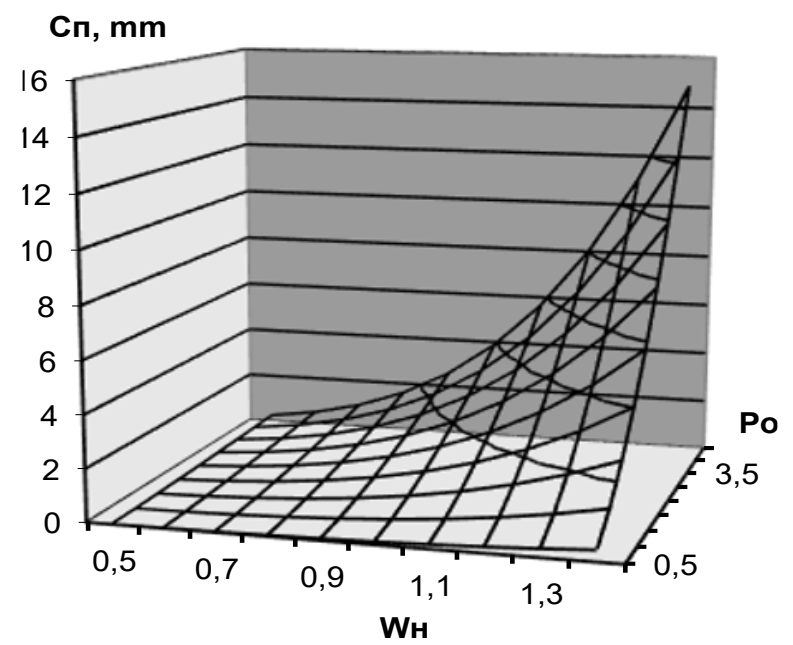

Fig. 2. Two-factor dependence of daily surface runoff on precipitation and soil moisture at runoff site No. 5

Table 2. Empirical coefficients of dependence (7) for experimental drainage sites

\begin{tabular}{|c|c|c|c|c|}
\hline $\begin{array}{c}\text { Option No. } \\
\text { (runoff site) }\end{array}$ & $\mathrm{a}_{0}$ & $\mathrm{~b}$ & $\mathrm{~b}_{1}$ & $\begin{array}{c}\text { Correlation ratio } \\
\mathrm{r}\end{array}$ \\
\hline 1 & 0,24 & 1,52 & 4,42 & 0,67 \\
\hline 2 & 0,05 & 1,11 & 2,79 & 0,76 \\
\hline 3 & 0,05 & 1,39 & 2,73 & 0,75 \\
\hline 4 & 0,01 & 1,19 & 2,63 & 0,73 \\
\hline 5 & 0,34 & 1,61 & 3,98 & 0,66 \\
\hline 6 & 0,06 & 1,13 & 3,24 & 0,68 \\
\hline
\end{tabular}

The limits of application of the obtained dependencies are as follows: $0 \leq \mathrm{P}_{0} \leq 1.45 ; 0.5$ $\leq \mathrm{W}_{\mathrm{H}} \leq 1.35$.

A quantitative analysis of formula (5) for individual options of experiments showed that at soil moisture equal to the runoff boundary $\mathrm{W}_{\mathrm{HB}}$, the maximum runoff caused by 
precipitation is noted in variants 5 and 1 (sites with steam and beets on a greater slope). According to (5), the surface runoff reaches 7.2 and $4.9 \%$ of the amount of precipitation, respectively. The minimum surface runoff is typical for the $4^{\text {th }}$ option (haymaking on a lower slope), where, with moisture at the level of the lowest moisture capacity, it is only $0.1 \%$ of precipitation.

Further implementation and generalization of experimental research is aimed at clarifying the dependences of the form (5) and their adaptation to the algorithm for calculating the water balance of the ameliorated soil.

\section{Conclusions}

The use of a constant calculated boundary of soil runoff at the level of the lowest soil moisture capacity leads to an unreasonable overestimation of the project parameters of drainage and moisture regimes and an irrational use of water resources. The performed research has shown that the variability of the soil runoff boundary should have a nonlinear character and take into account the discretization of water balance calculations. For an objective assessment of soil runoff, further scientific and experimental substantiation of its dependence on the main factors in specific soil-climatic and economic conditions is necessary.

\section{References}

1. V. I. Vikhrov. Resource-saving algorithms for calculating project norms for irrigation of herbs in Belarus. Resource-saving and energy-efficient technologies and equipment in irrigated agriculture. 1, 81 - 84 (2003)

2. I. A. Levshunov, V. I. Vikhrov. Influence of discretization of calculations of the water balance of reclaimed soil on the amount of runoff. Resource conservation and ecology in agriculture. 1, 232 - 233 (2005)

3. R. Dhungel, F. Fiedler. Water Balance to Recharge Calculation: Implications for Watershed Management Using Systems Dynamics Approach. Hydrology, 3(1), 13 (2016) https://doi.org/10.3390/hydrology3010013

4. Z. Shulan, Y. Xue-Yun, L. Lars. Soil Management Practice Effect on Water Balance of a Dryland Soil during Fallow Period on the Loess Plateau of China. Soil and Water Research. 11, 64-73, (2016) https://doi.org/10.17221/255/2014-SWR

5. M. Huang, L. Leung, M.Wigmosta, A.Coleman, Y. Ke, T. Tesfa, H. Li. Evaluating and improving CLM hydrologic processes for integrated earth system modeling at regional scales. AGU Fall Meeting Abstracts. (2010).

6. A.Volchak, A. Meshyk, Y. Mazhayskiy, O. Chernikova. Modeling dynamics of stored soil moisture at stage of control of structures of amelioration systems. Engineering for Rural Development, 19, 114-120 (2020) https://doi.org/10.22616/erdev.2020.19.tf026

7. O. B. Imamnazarov, T. O. Qosimov, M. R. Abdullaev. Balances of soil water of cotton rootable layer in experimental production sections. IJIERT - International Journal of Innovations in Engineering Research and Technology. 7(5), 318-321 (2020)

8. K. Zeinab, S. Seyed Hamidreza. Runoff Control using Soil Amendments (2018)

9. A.P. Likhatsevich, I.A. Romanov. Calculating soil water balance during short-term over moistening. Reclamation. 4(78), 7-17 (2016) 